$$
\begin{aligned}
& \text { دراسة امتزاز صبغة الأيوسين على سطح قثشور الحنطة }
\end{aligned}
$$

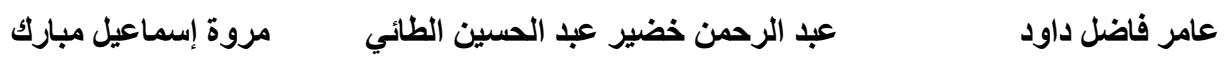

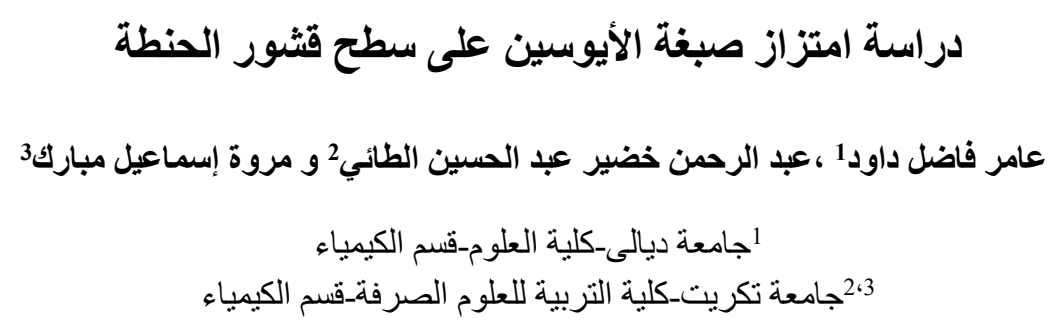

الخلاصة

في هذا البحث تم إز الة صبغة الأيوسين من المحاليل المائية على سطح نباتي (قثور الحنطة). تم تحديد زمن الاتزان لعملية

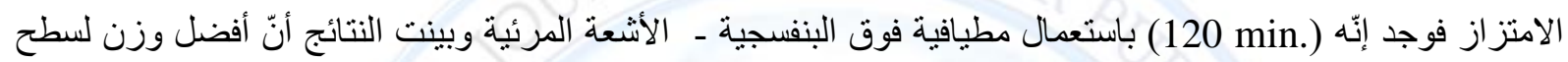
الماز هو (0.2 g). كذلك أجريت الدر اسة في مدى من الدو ال الحامضية (10)1-10). تم استعمال أيزوثيرم (لانكماير، فرندلش ، دوبنين وتمكن) إذوجد أنّ أفضل أيزوثيرم هو أيزوثيرم دوبنين. وكلك تم حساب كمية الامتز از في مدى من درجات الحر ارة (20-40 Cو فوجد إنّ كمية الامتز از تزداد بزيادة درجة الحرارة وهذا يبين ان التفاعل ماص للحر ارة وتم حساب قيم الدوال الثرموديناميكية لعملية الامتزاز و دراسة حركية للامتزاز فوجد ان الامتزاز يتبع معادلة المرتبة الثانية الكاذبة دهبة وحسبت ثو ابت السرع و الدو ال الثرموديناميكية للتنشيط للتفاعلين الامامي و العكسي. كلمات مفتاحية: -الامتز از ، أيزوثرمات، دراسة حركية، صبغة الايوسين، قشور الحنطة.

\title{
Study Eosin Dye Adsorption on the Surface Wheat Chaff
}

\author{
Amer Fadhil Dawood ${ }^{1}$, Abd AL-Rahman Khudheir AL- Taie ${ }^{2}$ and Marwa Ismail Mubarak ${ }^{3}$ \\ ${ }^{1}$ Diyala University -College of Science - Chemistry Department \\ ${ }^{2,3}$ Tikrit University - College of Education for Pure Science - Chemistry Department
}

\section{Received 4 May 2016 ; Accepted 5 June 2016}

\begin{abstract}
In this paper has been removed from the Eosin dye aqueous solutions on the surface Plant (wheat chaff). It was determined to equilibrium time the process of adsorption and found that (120 min.) Spectroscopy using ultraviolet - visible rays and the results showed that the best weight for the surface of the adsorbent is $(0.2 \mathrm{~g})$. Moreover, the study was conducted in a range of acidic state ( $\mathrm{pH}=1-10)$. Isotherm been used (for Langmuir, Freundlich, Dubinin, Temkin) as it was found that the best Isotherm is Isotherm Dubinin. And the amount of adsorption was
\end{abstract}




$$
\begin{aligned}
& \text { دراسة امتزاز صبغة الأيوسين على سطح قثشور الحنطة }
\end{aligned}
$$

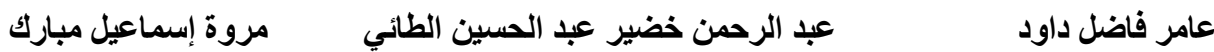

calculated in the range of temperatures $\left(20-40^{\circ} \mathrm{C}\right)$ and found that the amount of adsorption increasing with increasing temperature and this shows that the interaction endothermic was calculated valuable thermodynamic functions and was conducted kinetic study of the adsorption and found that the adsorption follows the equation second false constants were calculated velocities and thermodynamic functions activation of front and reverse reaction.

Keywords:-adsorption, Isotherms, Kinetic study, Eosin dye, Wheat chaff.

\section{المقدمة}

إنّ التلوث من المشاكل التي تتطلب معرفة كيفية التخلص منها والانسان له الدور الواضح يلعبه افي تفاقمها (1). ومن أحد أنو اعه التلوث البيئي و الذي يشمل تلوث التربة بسبب المو اد الكيميائية (2)، وتلوث الهو اء الذي يحدث بسبب احتراق الغابات و المركبات المتطايرة السامة وتلوث المياه الجوفية بسبب المركبات العضوية واللاعضوية المتسربة إلى المياه. ان تلوث المياه الجوفية ومياه الصرف الصحي يأتي أيضا من المؤسسات العامة و التجارية لنفايات الصناعية السائلة (3). ان من الصناعات التي تزيد مشكلة تلوث مياه الصرف الصحي هي صناعات صبغ المنسوجات و المو اد الغذائية و المو اد البلاستيكية التي تستخدم

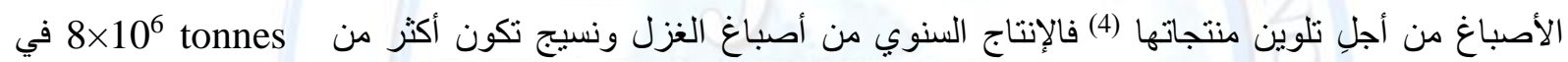
عام1990منها \% 10يتم تفريغها كنفايات سائلة (5) ولوحظ أنّ العديد من هذه الصبغات مسرطنة و المو اد المسرطنة هي المو اد الكيميائية التي تسبب مرض السرطان (6) ـ توجد طرق عدة لمعالجة تلوث المياه منها التناضح العكسي والتبادل الايوني والاكسدة الكيميائية والترشيح والامتزاز ويعد الامتزاز إحدى الطرق الأمنة و الفعالة في معالجة تلوث المياه والامتزاز باستخدام الكاربون المنشط هو الأكثر انتشار ا وسبب ذلك أنّ مسامية الكاربون العالية. إنّ عملية إزالة الصبغة عن طريق وليق الامتزاز باستخدام ماز بأقل تكلفة عملية ناجحة اقتصاديا ومن أمثلة المواد المازة هي قتشور الحنطة وقشور الأرز وقثور الفاكهة و الخشب (7). و هناك نو عين من الامتز از كيميائي وفيزيائي و هنالك عدة عو امل تؤثر على الامتز از منها حجم الجزيئات الممتزة ومسامية السطح الماز ودرجة الحرارة وزمن الاتزان والدالة الحامضية.

\section{المواد والطرق}

المواد والأجهزة

الصبغة التي استعملت في هذه الدر اسة هي صبغة الأيوسين وتسمى أيضا (eosin yellowish،eosin Y ws) ـ إنّ المادة المازة (السطح) التي تم استعمالها في هذه الدراسة هي قشور الحنطة التي تم الحصول عليها من سايلوا-ديالى إذ تم غسل قتشور الحنطة عدة مر ات لإز الة الثو ائب ومن ثم تم تجفيفها في الفرن لمدة ساعتين وبدرجة حر ارة 120مئوية ومن ثم طحنت بشكل مسحوق بقطر بm 75. إمّا الأجهزة التي استخدمت فهي: -مطياف الاشعة المرئية_فوق البنفسية (UV-Visible) لتحليل ومعرفة تركيز المادة الممتزة عند التوازن وحمام مائي ذب هز از ومسيطر على درجة حرارته. 


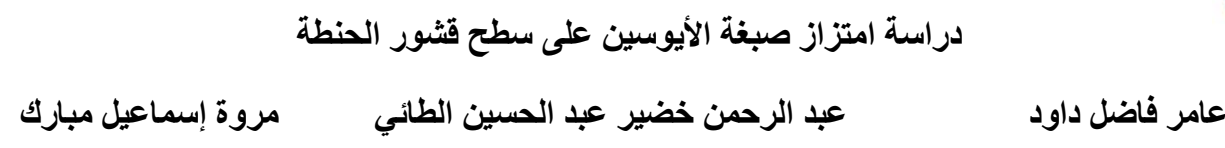

طريقة العمل

نم تعيين أيزوثرمات الامتزاز لصبغة الأيوسين من خلال تحضير عشرة تر اكيز من (20 ppm) من التركيز الأصلي لصبغة الأيوسين و الذي هو (25 ppm) إذ تم سحب (30ml) من كل تركيز ووضعت في قناني زجاجية سعة (50ml) وبتماس مع الوزن المحدد للسطح الماز و الذي هو (0.2 (0.2) لقثور الحنطة وتم تغطيتها جيدا ووضعت في حمام مائي مزود بهزاز بقوة(185 rpm) ومسيطر على درجة الحرارة عند 25 مئوية وبعد الوصول الى زمن الاتزان المحدد يتم ترشيحها

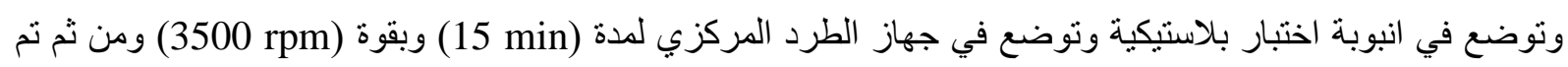

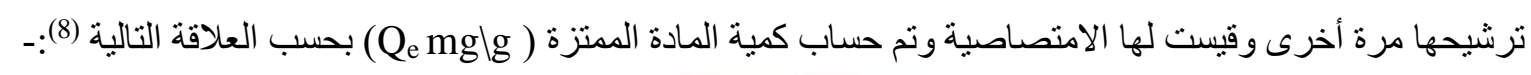
$Q_{e}=\frac{C_{o}-C_{e}}{m} \cdot V_{s o l}$

وتم دراسة حركية الامتزاز لصبغة الأيوسين على سطح قشور الحنطة من خلال تحضير 18 قنينة زجاجية سعة (50ml) ويوضع في كل قنينة (30ml) من صبغة الأيوسين ذو تركيز (10ppm) و(0.2g) من قثور الحنطة ويتم تغطيتها بأطباق بلاستيكية ووضعها في الحمام المائي المزود بهزاز ومسيطر على درجة الحر ارة عند 25 مئوية وبعده مرور خمسة دقائق

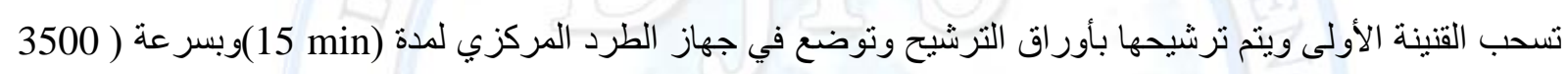
ومن ثم يتم ترشيحها مرة أخرى وتقاس لها الامتصاصية عند الطول الوجي المثبت بجهاز المطيافية الأشعة المرئية ـ

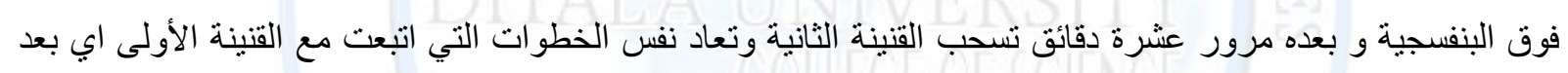
مرور كل خمسة دقائق تسحب قنينةو هكذا لمدة (120 min) لقشور الحنطة. وتكرر العملية عند درجة حر ارة 20,30,35,40 فئنة مئوية.

\section{النتائَج والمناقشة}

تعديا زمن الاتزان

هذه الخطوة مهمة من البحث بإجر اء در اسة حركية تهدف إلى متابعة تغير امتز از لصبغة قيد الدراسة مع الزمن وتحديد الزمن

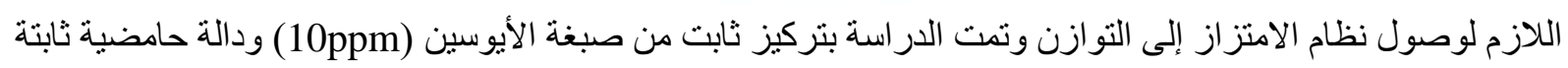

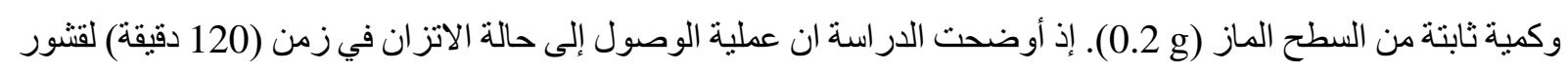
الحنطة، والنتائج موضحة في شكل (1) لقشور الحنطة. 
دراسة امتزاز صبغة الأيوسين على سطح قثور الحنطة

عبد الرحمن خضير عبد الحسين الطائي مروة إسماعيل مبارك عامر فاضل داود

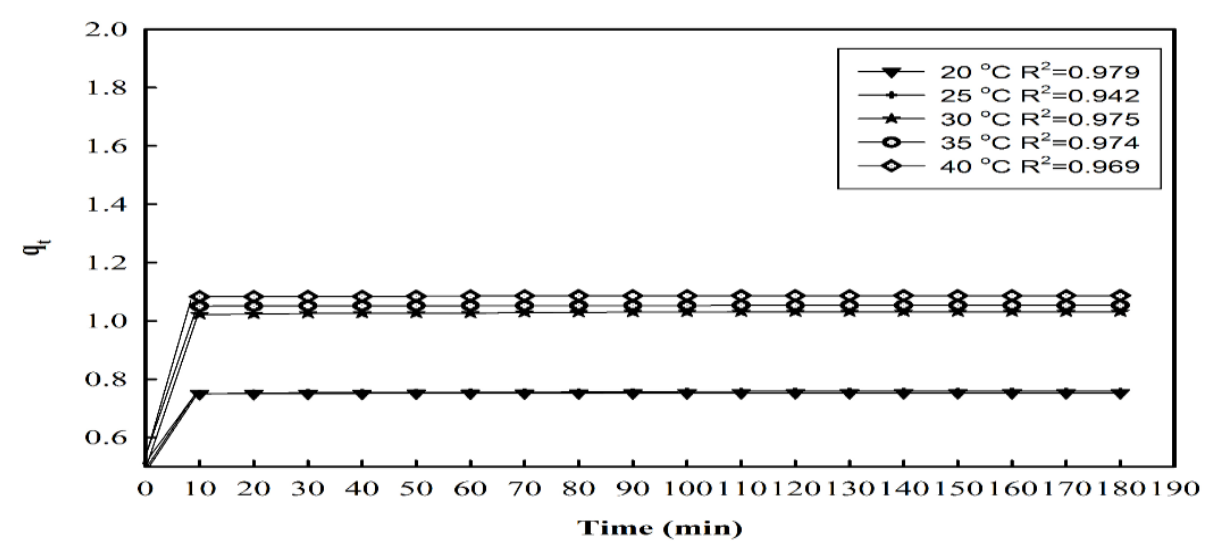

شكل (1) زمن الاتزان لامتزاز صبغة الأيوسين على سطح قشور الحنطة بلرجات حرارية مختلفة.

من خلال النتائج الموضحة أعلاه يتبين ان كمية المادة الممتزة بعد مرور 10دقائق تز اد وتستمر هذه الزيادة الى زمن معين ثم تبدأ من بعدها تقل تدريجيا أو تتبت تقريبا (9) نجد ان بعد مرور120دقيقة تتبت كمية المادة الممتزة أي إنّ امتزاز صبغة الأيوسين على سطح قشور الحنطة يتطلب ساعتين لوصول الصبغة إلى الاتزان مع السطح. والسبب هو ان عند بداية الامتزاز

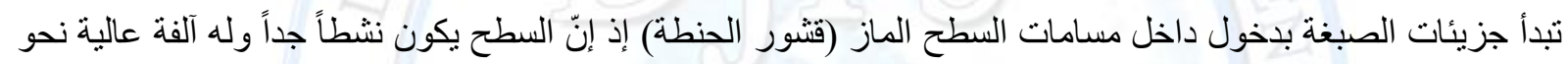
جزيئات الصبغة الى ان يتشبع السطح بجزيئات الصبغة بعدها تبدأ كمية المادة الممتزة تقل أو تثبت تدريجيا.

وزن السطح الماز

إنّ تأثير وزن سطح الماز على امتزاز صبغة الأيوسين تم در استه من خلال تغير وزن السطح الماز (قثور الحنطة) ضمن

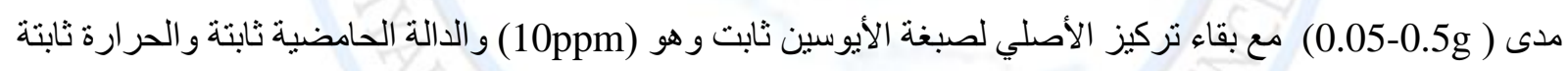

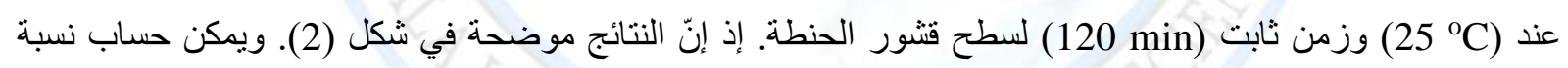

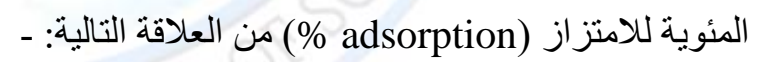

\%adsorption $=\frac{C_{o}-C_{e}}{C_{o}} \times 100$ 
دراسة امتزاز صبغة الأيوسين على سطح قثور الحنطة

عبد الرحمن خضير عبد الحسين الطائي مروة إسماعيل مبارك

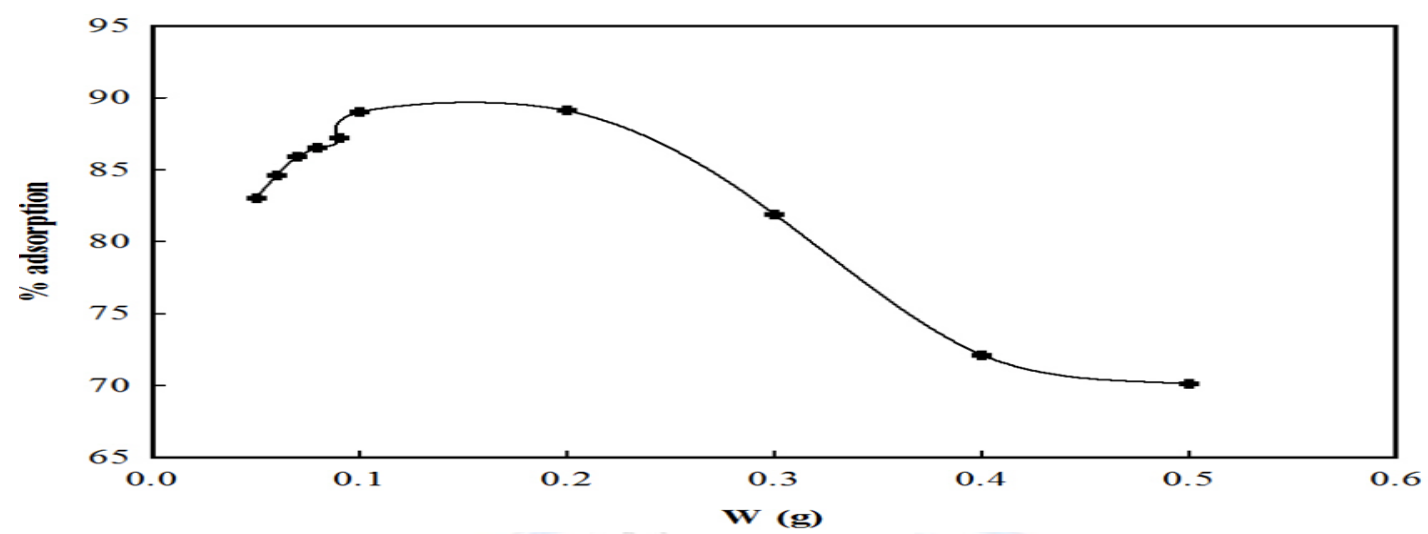

شكل (2) وزن السطح الماز ونسبة المئوية للامتزاز لصبغة الأيوسين على سطح قثور الحنطة.

إنّ نسبة المئوية للامتز از نجد أنّها تزداد مع زيادة وزن السطح الماز (قتُور الحنطة) وصولا إلى وزن (0.2g) إنّ السبب يعود إلى توفر كبير في مواقع التبادل أو زيادة المساحة السطحية التي يحدث عليها الامتز از (10)

تأثير الدالة الحامضية

إنّ تأثير الدالة الحامضية على امتزاز صبغة الأيوسين على السطح قشور الحنطة نم دراسته بتغير الدالة الحامضية ضمن مدى (10-7-4) وبتر اكيز مختلفة من صبغة الأيوسين ضمن مدى (2-20ppm) مع الحفاظ على درجة الحر ارة ثابتة عند $25{ }^{\mathrm{O}} \mathrm{C}$

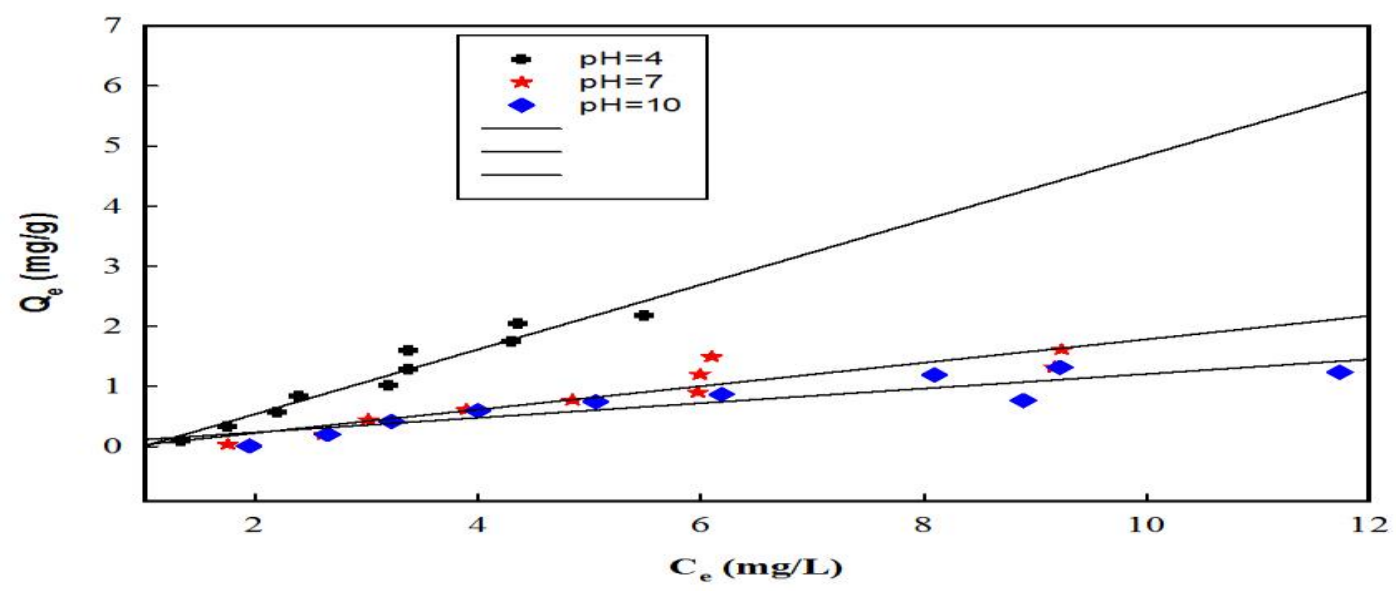

شكل (3) تأثير الدالة الحامضية على امتزاز صبغة الأيوسين على سطح قشور الحنطة عند درجة حرارة C C 


\section{دراسة امتزاز صبغة الأيوسين على سطح قثشور الحنطة \\ عبد الرحمن خضير عبد الحسين الطائي مروة إسماعيل مبارك \\ عامر فاضل داود}

إنّ الدالة الحامضية تؤثر على السطح الماز والمادة الممتزة وعلى التداخلات التي تحدث بينهما. تم التوصل إلى إنّ كمية الامتز از لصبغة الأيوسين على سطح قثور الحنطة تقل مع زيادة الدالة الحامضية إنّ السطح يحتوي على مجاميع (OH) وفي المحلول الحامضي ذو(pH=4) تزداد الثحنة الموجبة على السطح نتيجة كثرة البروتونات، وان زيادة تركيز أيونات

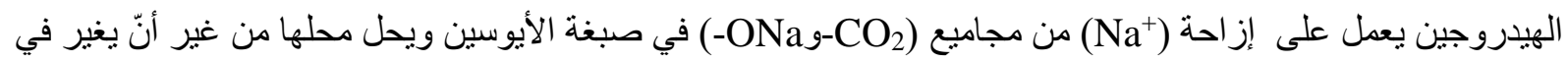
اللون أو الطول الموجي الأعظم لذلك نسبة التداخل تزداد بين الصبغة والسطح من خلال الارتباط بين ذرات الأوكسجين لصبغة الأيوسين و السطحين. بالتالي يزداد ميل الصبغة للارتباط بسطح أكثر من ميلها للارتباط بجزيئات المذيب. لذلك تزد داد

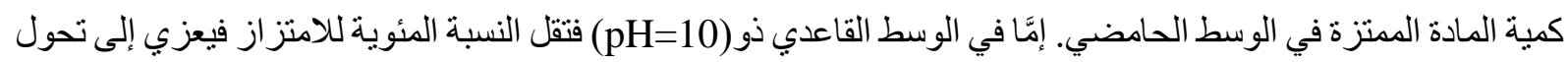
هذه الصيغة إلى ملح إذ تتحول مجموعة الهيدروكسيل إلى ايون الفينوكسيد مولدة شحنة سالبة على ذرة الأوكسجين وبذلك

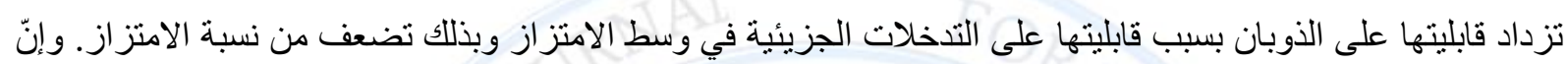
السطح سوف يكتسب شحنة سالبة من خلال المحلول. وإنّ مجموعات الهيدروكسيل تعمل على سحب (Na) من صن صبغة الأيوسين من مجموعة (-ONa و-CO2 الموجي الأعظم. بالتالي سوف يحدث تنافر شديد للثحنات المتماتلة للصبغة و السطحين فتقل كمية المادة الممثزة على السطح لحدوث تتافر الالكتروستانيكي بينهما. إمّّا عند دراسة أفضل دالة حامضية لسطح فقد وجدت عند (pH=1) إذ كلما يكون الوسط حامضي تزداد نسبة لمئوية للامنز از (\% adsorption) ونتائج موضحة في شكل (4)

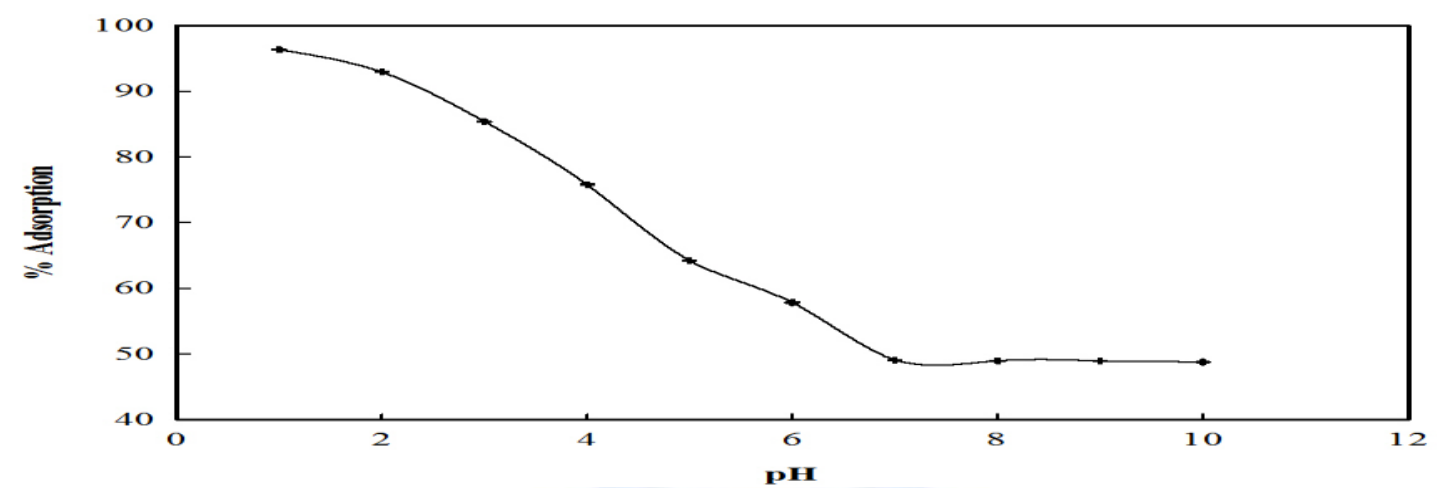

شكل (4) تأثير تغير الدالة الحامضية على النسبة المئوية لامتزاز صبغة الايوسين على سطح مخلفات دبس التمر.

تأثير درجة الصرارة على الامتزاز تم دراسة تأثير درجة الحرارة على امتزاز صبغة الأيوسين في مدى (20 Co C موضحة في شكل (5). النتائج تثبر إلى إنّ كمية الامتز از لصبغة الأيوسين تزداد مع زيادة درجة الحرارة. إذ يمكن تفسير

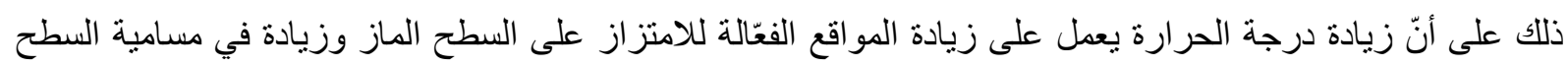
وزيادة حجم المسام في السطح الماز ، وكذلك زيادة درجة الحرارة يعمل على زيادة معدل انتشار الجزيئات الممتزة على طبقة السطح الماز وقلة لزوجة المحلول وكنلك زيادة كمية الامتزاز نتيجة زيادة حركة جزيئات الصبغة بزيادة الطاقة الحركية 
دراسة امتزاز صبغة الأيوسين على سطح قثور الحنطة

عبد الرحمن خضير عبد الحسين الطائي مروة إسماعيل مبارك

عامر فاضل داود

(111,110). نتيجة تكسر قوى الارتباط بينهما. ويتطابق هذا الكلام مع الدو ال الثرموديناميكية و التي وجدت أنّ التغير في الأنثالبي

هو موجب أي إنّ عملية الامتزاز ماصة للحرارة.

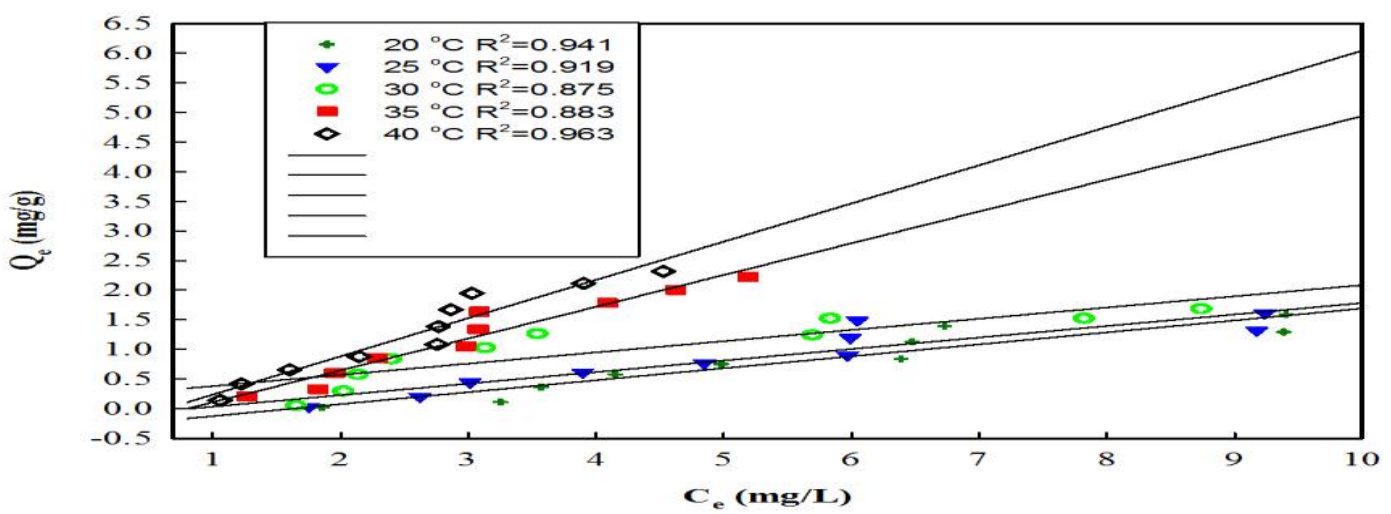

شكل (5) تأثير تغير درجة الحرارة على امتزاز صبغة الايوسين على سطح قشور الحنطة.

حساب الاوال الثرموديناميكية

تعد قيم الدوال الثرموديناميكية مهمة جدا في تفسير الكثير من التفاعلات (ولاسيما عملية الامتزاز) من حيث اتجاه سير ها وطبيعة القوى المسيطرة عليها فضلا عن أنّها تعطي وصفا جيدا عن طبيعة انتظام الجزيئات في الانظمة المختلفة الناتجة عن التدخلات الجزيئية بجميع انو اعها. إذ تمثل قيمة الحرارة أو الأنثالبي (SH ) مقياسا مباشر ا لقوى التداخل بين الجزيئة الممتزة و السطح الماز وتم حساب قيمة الأنثالبي باستخدام معادلة فونت هوف و التي هي: -

$K_{C}=\mathbf{A e}^{-\Delta H^{o} / R T}$

$\ln \mathrm{X}_{\mathrm{m}}=-\frac{\Delta H^{o}}{\mathrm{RT}}+\mathrm{k}$

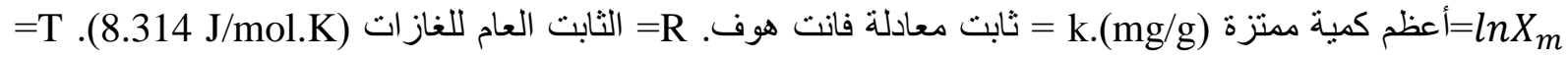

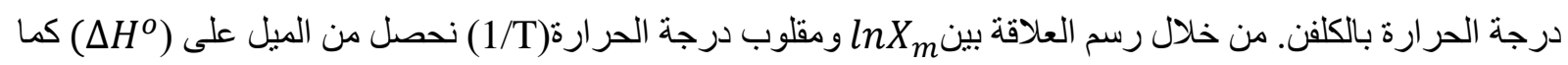
في شكل (6). ونتائج الدوال الثرموديناميكية موضحة في جدول (1). ويمكن الحصول على التغير في الطاقة الحرة (التي يتم التعرف من خلالها على تلقائية أو عدم تلقائية التفاعل من العلاقة التالية: -

$\Delta G^{o}=-\mathrm{RT} \ln \mathrm{K}$ 
دراسة امتزاز صبغة الأيوسين على سطح قثور الحنطة

عبد الرحمن خضير عبد الحسين الطائي مروة إسماعيل مبارك

عامر فاضل داود

إذ تبين ان امتز از صبغة الأيوسين على سطح تككن تلقائية ومن خلال علاقة جبس يمكن تحديد التغير في الانتروبي (US

من العلاقة التالية:-

$\Delta G^{o}=\Delta H^{o}-\mathrm{T} \Delta S^{o}$

$\Delta S^{o}=\frac{\Delta H^{o}-\Delta G^{o}}{\mathrm{~T}}$

إذ إنّ تغير في الانتروبي لصبغة الأيوسين على سطح قشور الحنطة يكون موجب هذا يدل على ان جزيئات الممتزة صبغة لأيوسين ماز الت في حركة مستمرة على السطح أكثر من المحلول.

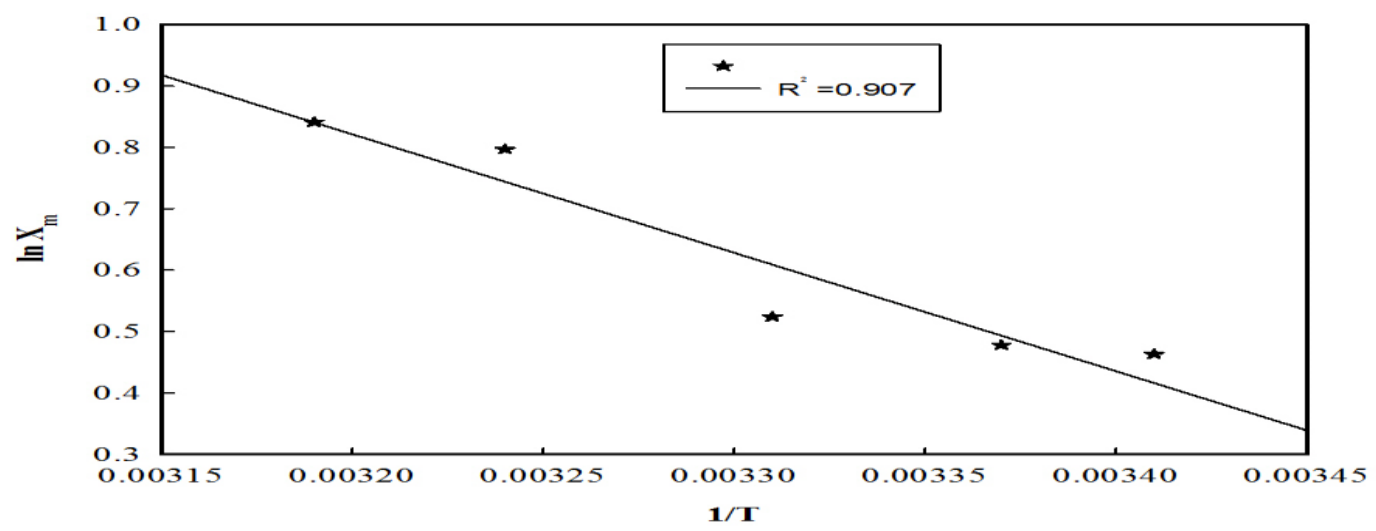

شكل(6) كميات الامتزاز العظى (In Xm) ودرجات الحرارة(T) المختلفة بكلفن (K) لصبغة الأيوسين على سطح قثور الحنطة

جدول (1) قيم الدوال الثرموديناميكية لصبفة الأيوسين على سطح قشور الحنطة وبخمس درجات حرارية .(20,25,30,35,40 $\left.{ }^{\circ} \mathrm{C}\right)$

\begin{tabular}{|c|c|c|c|c|c|c|}
\hline $\begin{array}{c}\mathbf{C}_{\mathbf{o}} \\
(\mathbf{m g} / \mathbf{L})\end{array}$ & $\begin{array}{c}\text { Thermodynamic } \\
\text { Function }\end{array}$ & $\mathbf{2 0}^{\circ} \mathbf{C}$ & $\mathbf{2 5}^{\circ} \mathbf{C}$ & $\mathbf{3 0}^{\circ} \mathbf{C}$ & $\mathbf{3 5}^{\circ} \mathbf{C}$ & $\mathbf{4 0}^{\circ} \mathbf{C}$ \\
\hline \multirow{3}{*}{$20 \mathrm{ppm}$} & $\begin{array}{c}\Delta \boldsymbol{H}^{\mathbf{0}} \\
\mathbf{k J . m o l}\end{array}$ & \multicolumn{5}{|c|}{+16.036} \\
\cline { 2 - 7 } & $\begin{array}{c}\Delta \boldsymbol{G}^{\mathbf{0}} \\
\mathbf{k J . m o l}\end{array}$ & -0.290 & -0.377 & -0.638 & -2.680 & -3.198 \\
\cline { 2 - 7 } & $\begin{array}{c}\Delta \boldsymbol{S}^{\mathbf{0}} \\
\mathbf{J}^{-1} \mathbf{m o l}^{-1} \mathbf{K}^{-1}\end{array}$ & +0.0557 & +0.0551 & +0.0550 & +0.0607 & +0.0614 \\
\hline
\end{tabular}


دراسة امتزاز صبغة الأيوسين على سطح قثور الحنطة

عبد الرحمن خضير عبد الحسين الطائي مروة إسماعيل مبارك
عامر فاضل داود

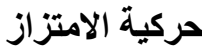

أُجريت الدر اسة الحركية على امتزاز صبغة الأيوسين باستخدام طريقة الوجبة (Batch method) و عند تركيز ( 10ppm) وفي مدى من الدرجات الحر ارية (293-313K) مطلقة وتم تطبيق معادلة الآتي:-

$\ln (a-x)=\ln a-k_{1} t$

$\ln \left(C_{o-} q_{t}\right)=\ln C_{o}-k_{1} t$

نحصل من الميل على ثابت سر عة للتفاعل الأمامي (K1) من التقاطع على (lnqe) وتمثل هذه المعادلة المرحلة الابتدائية

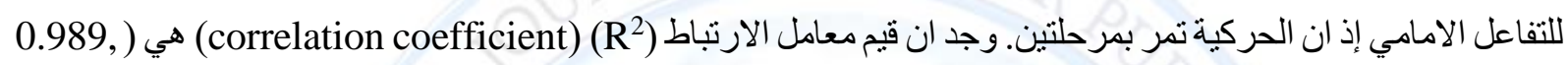

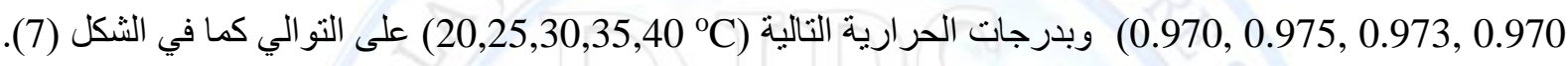
وتم تحليل النتائج امتزاز صبغة الأيوسين وفق معادلات المرتبة الأولى الكاذبة لأرجركرين للتفاعل العكسي و هي تمثل مرحلة الثانية ومعادلة هي:-

$\ln \left(q_{e}-q_{t}\right)=\ln q_{e}-\left(K_{1}+K_{-1}\right) t$

من خلال الرسم بين (ln (qe-qt ) و الزمن من ميل نحصل على ثابت السر عة التفاعل الأمامي و ثابت السرعة التفاعل

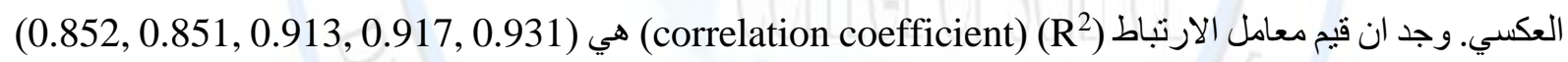
وبدرجات الحر ارية التالية (20,25,30,35,40 C على التو الي كما في شكل (8). و تم تحليل النتائج وفق معادلة المرتبة

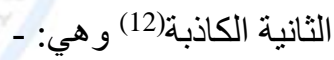

$\frac{\mathrm{t}}{\mathrm{q}_{\mathrm{t}}}=\frac{1}{\mathrm{~K}_{2} \mathrm{q}_{\mathrm{e}}^{2}}+\frac{1}{\mathrm{q}_{\mathrm{e}}} \mathrm{t}$

$\mathrm{h}=\mathrm{K}_{2} \mathrm{q}^{2}$

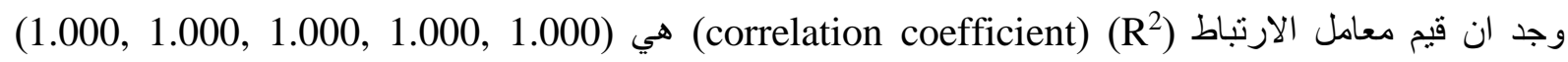
وبدرجات الحر ارية التالية (20, 25, 30, 35, 40 (2) على التو الي كما في شكل (9). من قيم معامل الارتباط يتبين أنّ هذه المرتبة ملائمة لامتزاز صبغة الأيوسين على سطح قثور الحنطة. من خلال النتائج إنّ عملية الامتز از تمر بمر حلثنين مرحلة ابتدائية تكون سريعة عملية الامتزاز عالية بحيث يصعب تتبع در استها مركب و لا يمكن حساب طاقة التنشيط منها ويتبعها مرحلة بطيئة بعدها يصل النظام الامتز از إلى حالة التو ازن و على غر ار التفاعلات المعاكسة وبالاستفادة من وصول الامتز از لهن إلى حالة الاتزان نستخدم نموذج لارجركرين. وعند دراسة عملية الامتزاز في درجات حرارية مختلفة وباستخدام معادلة أر هينوس و التي تصف العلاقة بين قيمة ثابت السر عة للتفاعل مع درجة الحرارة وردين وهي: - 
دراسة امتزاز صبغة الأيوسين على سطح قثور الحنطة

عبد الرحمن خضير عبد الحسين الطائي مروة إسماعيل مبارك

عامر فاضل داود

$\ln K=\ln A-\frac{E}{R T}$

و التي من خلال رسم العلاقة بين (ln k1) مقابل مقلوب درجة الحرارة بكلفن نحصل من الميل على قيمة طاقة التنشيط للتفاعل الأمامي ومن رسم العلاقة بين (ln k-1) مقابل مقلوب درجة الحر ارة بكلفن نحصل من ميل على قيمة طاقة التنشيط للتفاعل العكسي. وكذلك إنّ ثابت الاتزان يساوي حاصل قسمة ثابت السر عة التفاعل الأمامي على ثابت السرعة التفاعل العكسي كما في شكل (10) و شكل (11).إنّ متغير ات المرتبة الأولى الكاذبة و الثانية الكاذبة مدرجة في جدول (2). ويمكن حساب الدو ال الثرموديناميكية لتنشيط لكلا الاتجاهين باستخدام المعادلات الآتية: -

$\Delta \boldsymbol{H}^{*}=\boldsymbol{E}-\boldsymbol{R} \boldsymbol{T}$

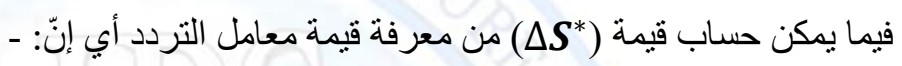

$\mathbf{A}=\frac{K T}{h} \mathbf{e}^{\left(1+\frac{\Delta S^{*}}{R}\right)}$

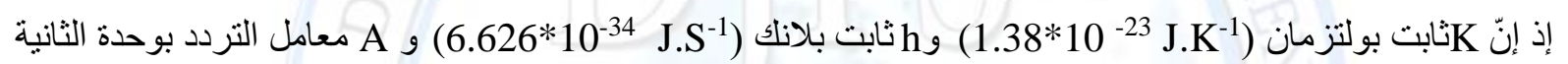
ويؤخذ ln لمعادلة الاخيرة مع اعادة الترتيب فتصبح كالاتي:-

$\Delta S^{*}=R\left[\ln A \cdot \ln \left[\frac{K T}{h}\right]-1\right]$

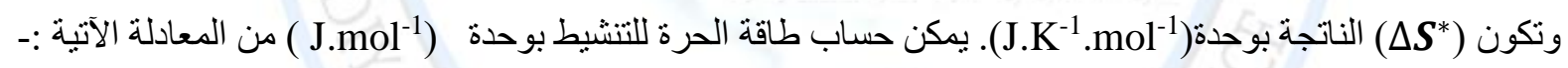

$\Delta \boldsymbol{G}^{*}=\Delta \boldsymbol{H}^{*}-\boldsymbol{T} \Delta \boldsymbol{S}^{*}$

كذللك تثير القيم الموجبة ( الامتزاز ويمكن حساب قيمة انثالبي الامتزاز من الفرق بين أنتالبي الامتزاز للتنشيط في الاتجاه الأمامي و العكسي (ومن

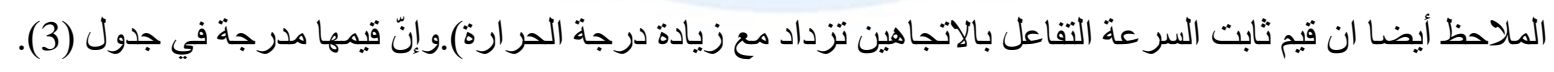




\section{DIYALA JOURNAL FOR PURE SCIENCES}

دراسة امتزاز صبغة الأيوسين على سطح قثور الحنطة

عبد الرحمن خضير عبد الحسين الطائي مروة إسماعيل مبارك عامر فاضل داود

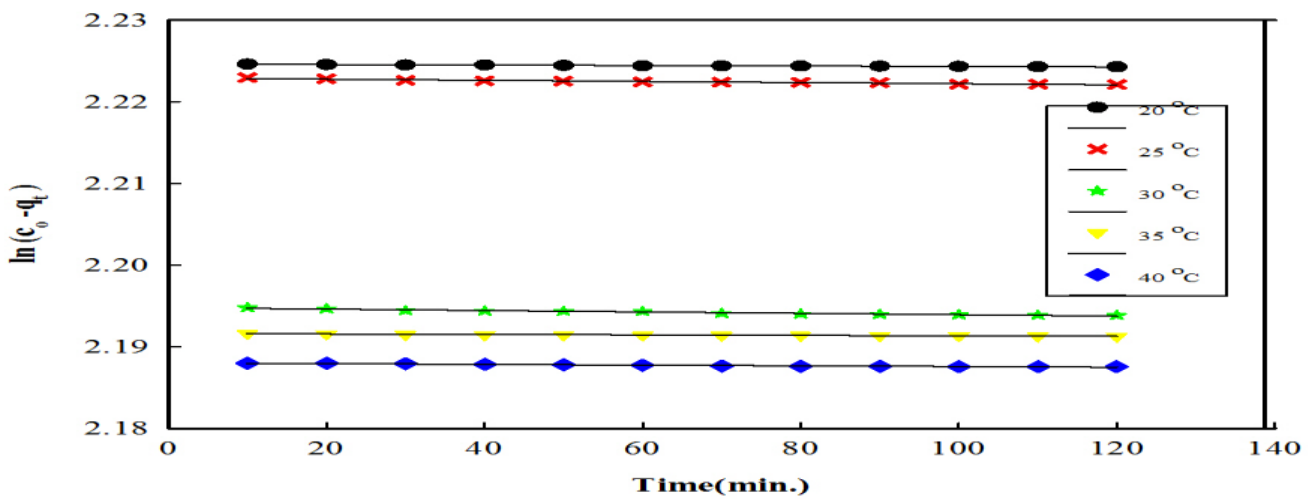

شكل (7) معادلة المرحلة الابتدائية للتفاعل العكسي لامتزاز صبغة الأيوسين على سطح قثور الحنطة وبخمس درجات

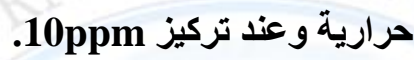

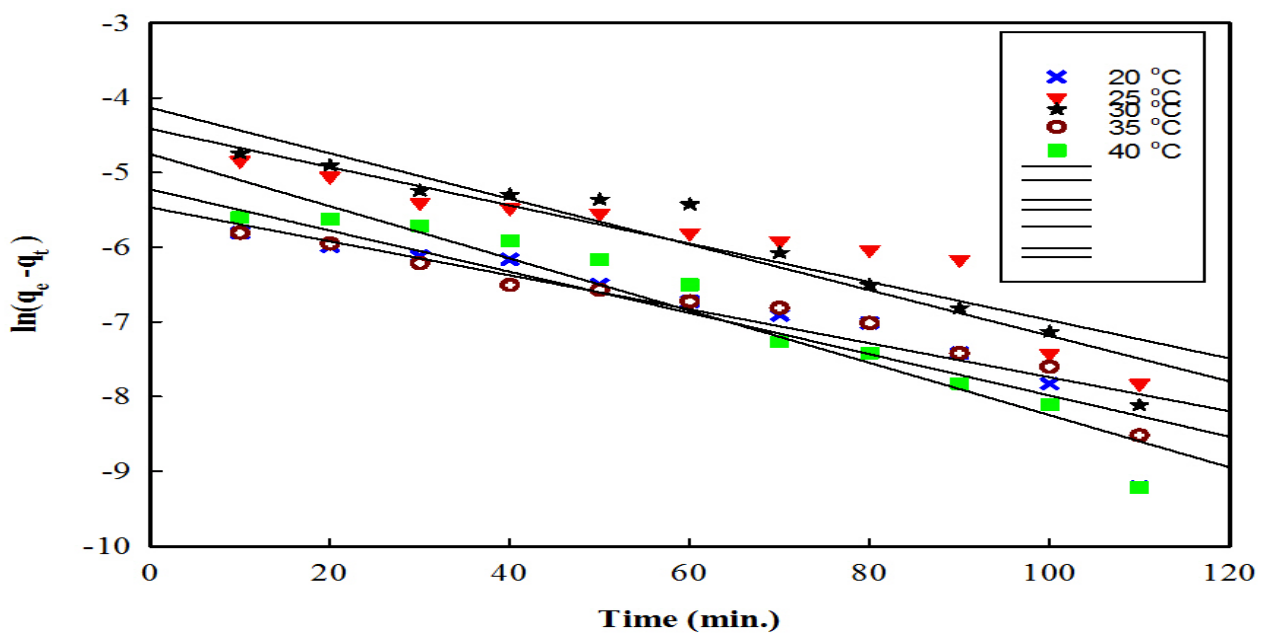

شكل (8) المرتبة الأولى الكاذبة لامتزاز صبغة الأيوسين على سطح قثور الحنطة وبخمس درجات حرارية وعند تركيز $.10 p p m$ 


\section{DIYALA JOURNAL FOR PURE SCIENCES}

دراسة امتزاز صبغة الأيوسين على سطح قثور الحنطة

عبد الرحمن خضير عبد الحسين الطائي مروة إسماعيل مبارك

عامر فاضل داود

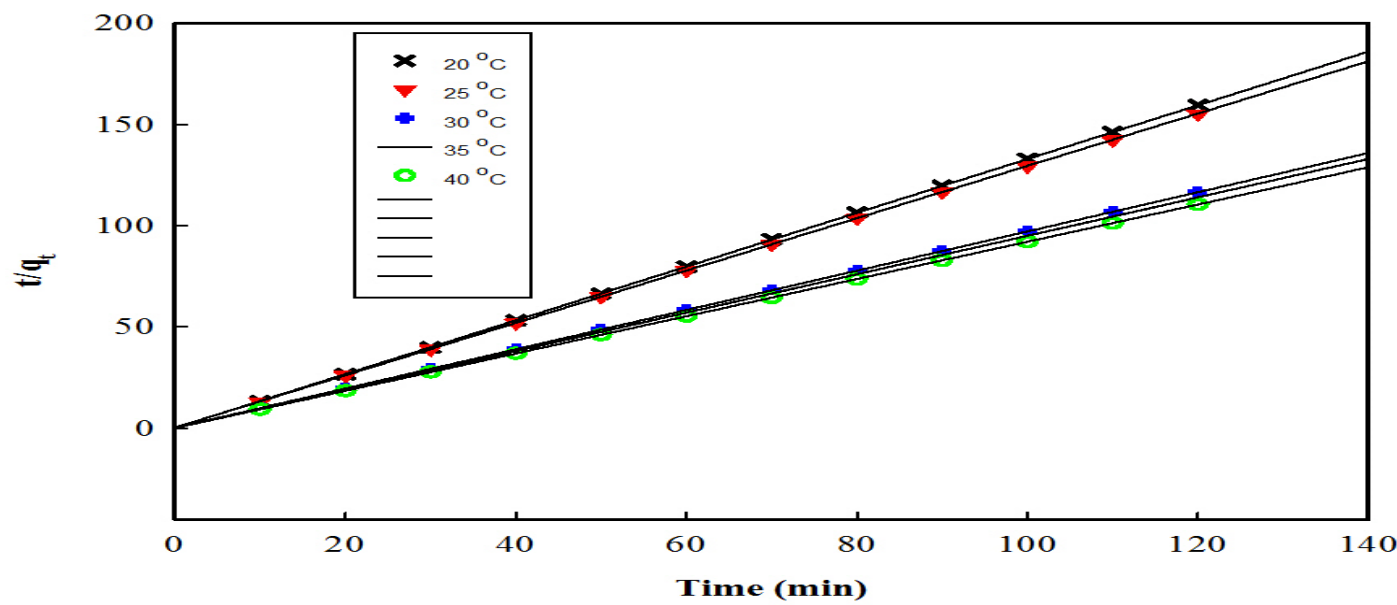

شكل (9) المرتبة الثانية الكاذبة لامتزاز صبغة الأيوسين على سطح قثور الحنطة وبخمس درجات حرارية وعند تركيز

$.10 p p m$

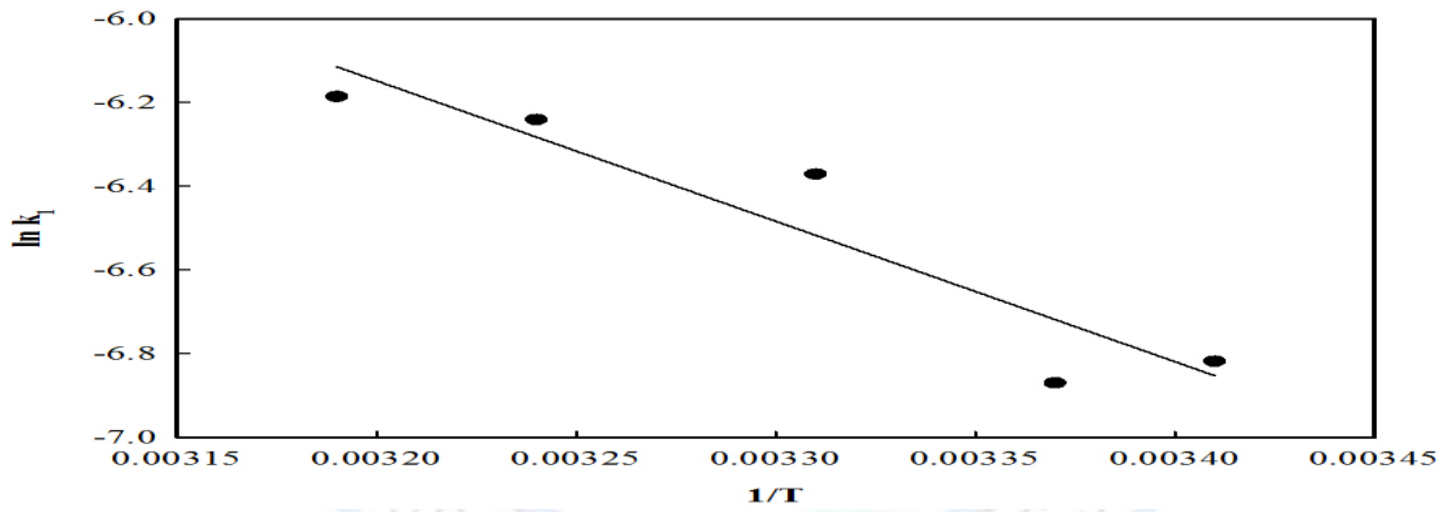

شكل (10) معادلة أرهينوس لتفاعل بالاتجاه الأمامي لامتزاز صبغة الأيوسين على سطح قثنور الحنطة.

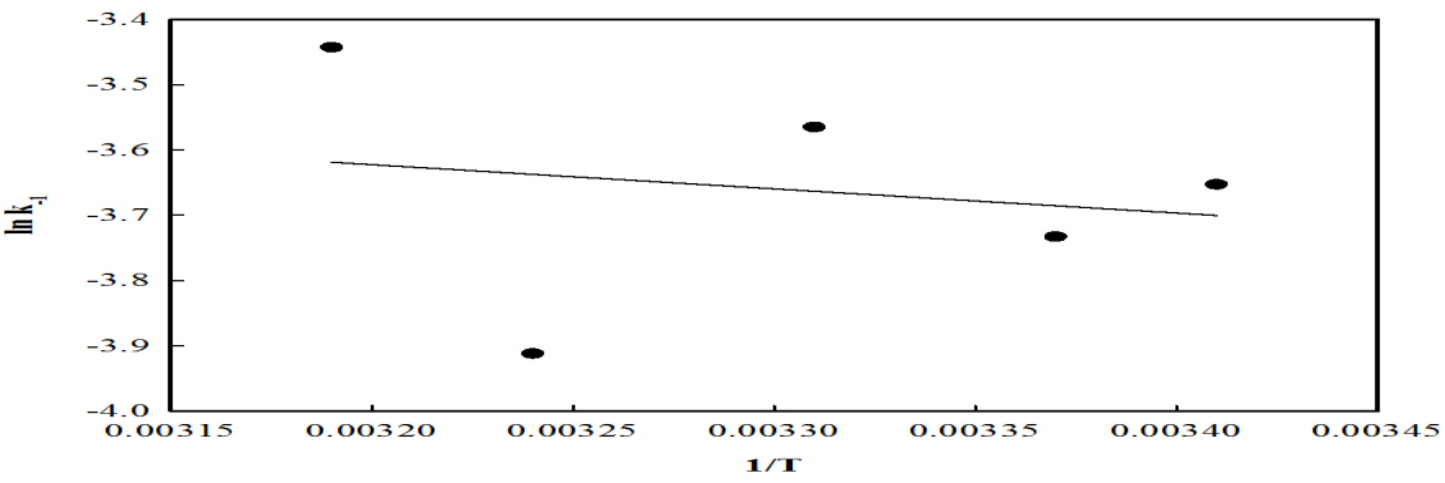

شكل (11) معادلة أرهينوس لتفاعل بالاتجاه العكسي لامتزاز صبغة الأيوسين على سطح قثور الحنطة. 
جدول (2) متغيرات مرتبة الأولى الكاذبة والثانية الكاذبة لامتزاز صبغة الأيوسين على سطح قثور الحنطة وبخمس

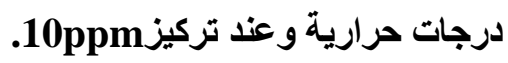

\begin{tabular}{|c|c|c|c|c|c|c|c|c|c|}
\hline \multirow{7}{*}{$\begin{array}{c}\mathrm{C}_{\mathrm{o}} \\
10 \mathrm{pp} \\
\mathrm{m}\end{array}$} & \multirow{2}{*}{$\mathbf{T}\left(\mathbf{c}^{0}\right)$} & \multirow{2}{*}{$\underset{(\text { exp.) }}{\mathbf{q}_{\mathrm{e}}}$} & \multicolumn{3}{|c|}{ pseudo-first -order } & \multicolumn{4}{|c|}{ pseudo-second -order } \\
\hline & & & $\underset{\text { (calc.) }}{\mathbf{q u}_{\mathrm{e}}}$ & $\underset{\mathbf{m i n}^{-1}}{\mathbf{K}_{1}}$ & $\mathbf{R}^{2}$ & $\begin{array}{c}\mathbf{q}_{\mathbf{e}} \\
\text { (calc.) }\end{array}$ & $\begin{array}{c}\mathbf{K}_{2} \\
\text { g.mg}{ }^{1} \\
\text { min }^{-1}\end{array}$ & H & $\mathbf{R}^{2}$ \\
\hline & 20 & 1.101 & 8.899 & 5.800 & 0.854 & 1.140 & 1.303 & 1.696 & 0.985 \\
\hline & 25 & 1.083 & 8.917 & 3.966 & 0.984 & 1.083 & 17.75 & 20.820 & 1.000 \\
\hline & 30 & 1.075 & 8.926 & 1.166 & 0.667 & 1.076 & 5.076 & 5.878 & 1.000 \\
\hline & 35 & 0.833 & 9.170 & 1.056 & 0.825 & 0.834 & 5.809 & 4.043 & 1.000 \\
\hline & 40 & 0.828 & 9.171 & 4.100 & 0.679 & 0.828 & 15.666 & 10.903 & 1.000 \\
\hline
\end{tabular}

الجدول (3) ثوابت السرع بالاتجاه الأمامي والعكسي ودوال الثرموديناميكية للمعقد المنشط لامثزاز صبغة الأيوسين على سطح قثور الحنطة.

\begin{tabular}{|c|c|c|c|c|c|c|c|c|}
\hline \multirow[b]{2}{*}{$\mathbf{T}\left(\mathbf{c}^{0}\right)$} & \multicolumn{4}{|c|}{ التفاعل بالاتجاه الامامي } & \multicolumn{4}{|c|}{ التفاعل بالاتجاه العكسي } \\
\hline & $\mathbf{K}_{\mathbf{1}}$ & $\Delta \boldsymbol{H}^{*}$ & $\Delta \boldsymbol{S}^{*}$ & $\Delta \boldsymbol{G}^{*}$ & $K_{-1}$ & $\Delta \boldsymbol{H}^{*}$ & $\Delta \boldsymbol{S}^{*}$ & $\Delta \boldsymbol{G}^{*}$ \\
\hline 20 & -6.676 & 2308.336 & $216^{-} 187$ & 61034.513 & -3.623 & 2154.921 & 238.451 & 68442.11 \\
\hline 25 & -6.334 & 2349.906 & $\begin{array}{c}- \\
216.323 \\
\end{array}$ & 62114.526 & -3.291 & $\begin{array}{c}- \\
2196.491 \\
\end{array}$ & 238.592 & 68904.103 \\
\hline 30 & -6.137 & 2391.476 & 216.466 & 63197.903 & -3.387 & $\begin{array}{c}- \\
2238.061 \\
\end{array}$ & 238.730 & 70097.310 \\
\hline 35 & -5.884 & 2433.046 & 216.602 & 64280.646 & -3.141 & 2279.631 & 238.867 & 71291.404 \\
\hline 40 & -6.141 & $\begin{array}{c}- \\
2474.616 \\
\end{array}$ & 216.736 & 65364.180 & -3.417 & 2321.202 & $\begin{array}{c}- \\
239.001 \\
\end{array}$ & 72486.048 \\
\hline$E^{*}$ & \multicolumn{4}{|c|}{127.6656} & \multicolumn{4}{|c|}{281.08054} \\
\hline
\end{tabular}

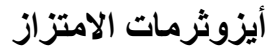

إنّ معلومات التي تعطيها أيزوثرمات الامتزاز مهمة. إذ أنّها تعطي فكرة عن كيفية توزيع الجزيئات بين الطور السائل و الطور

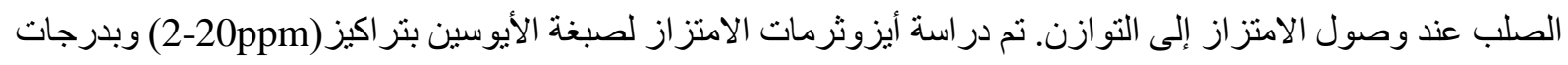
حر ارية (20,25,30,35,40 ) ونتائج موضحة في شكل (5). إنّ كل أيزوثرمات الامتز از لصبغة الأيوسين تشير إلى أنّها من نوع S بحسب تصنيف Giles. الأيزوثيرم من نوع S يعتمد على افتر اضيات أيزوثيرم فرندلخ، و التي تتضمن أنّ السطح الماز يكون غير متجانس. و هذه الخاصية عامة والسبب يعود إلى اختلاف مو اقع الامتزاز الغير مشبعة واختلاف الطاقة. إنّ نتائج الامتز از حلت وفق أيزوثيرم لانكماير الخطية كما في شكل (12) و التي هي: - 
دراسة امتزاز صبغة الأيوسين على سطح قثور الحنطة

عبد الرحمن خضير عبد الحسين الطائي مروة إسماعيل مبارك

$\frac{\mathrm{C}_{\mathrm{e}}}{\mathrm{Q}_{\mathrm{e}}}=\frac{1}{\mathrm{~K}_{\mathrm{l}} \mathrm{q}_{\max }}+\frac{1}{\mathrm{q}_{\max }}$

إنّ قيم معامل الارتباط (R2) و التي تكون بين مدى (0.392-051) نلاحظ أنّها قلليلة مما يدل على عدم ملائمة هذه المعادلة لنتائج امتزاز صبغة الأيوسين على السطح قشتور الحنطة.

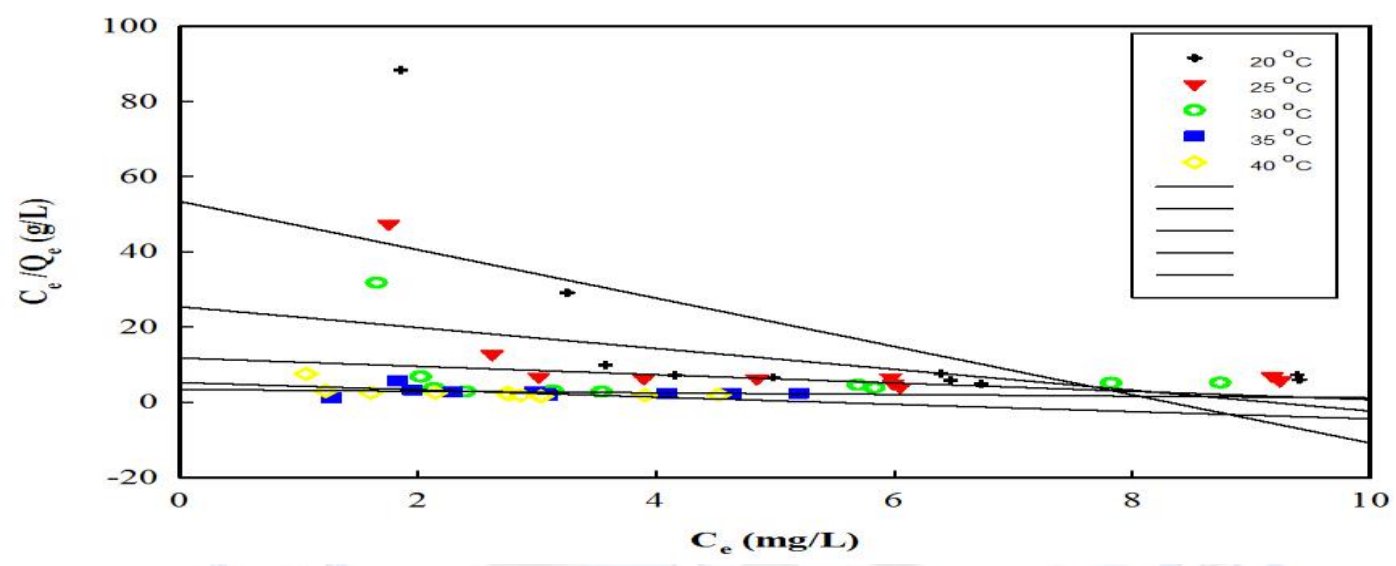

شكل (12) أيزوثيرم لانكماير لصبغة الأيوسين على سطح قشور الحنطة.

وتم تحليل نتائج امتزاز صبغة الأيوسين على السطح قشور الحنطة وفق أيزوثيرم فرندلخ الخطية والتي هي: -

$\ln Q_{e}=\ln K_{F}+\frac{1}{n} \ln C_{e}$

ونتائج موضحة في شكل (13). ومتغير ات أيزوثيرم فرندلخ موضحة في جدول (4).

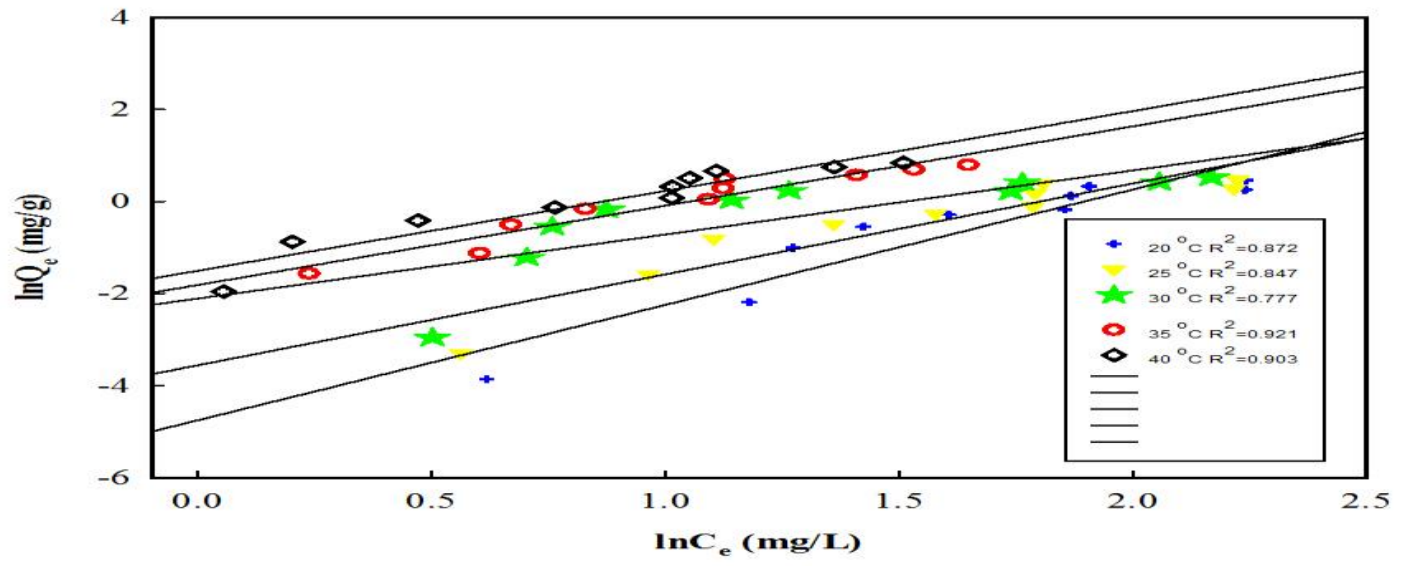

شكل (13) أيزوثيرم فرندلخ لصبغة الأيوسين على سطح قشور الحنطة. 
دراسة امتزاز صبغة الأيوسين على سطح قثور الحنطة

عبد الرحمن خضير عبد الحسين الطائي مروة إسماعيل مبارك

عامر فاضل داود

إنّ قيم معامل الارتباط (R2) و التي تكون بين مدى (0.921 -0.777) إذ نلاحظ ملائمة معادلة فرندلخ لنتائج امتزاز صبغة

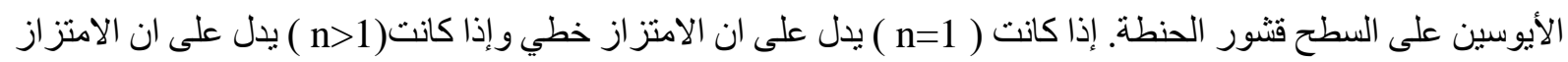

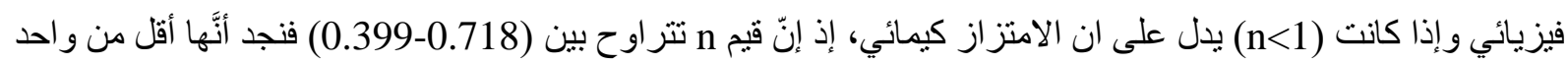
مما يشير إلى أنَّ الامتز از كيمائي (أي تربطه قوى كيميائية). إنّ قيمة n تتراوح بين (10-1) يدل على ان الامتزاز جيد. وتم تحليل النتائج وفق أيزوثيرم دوبنين الخطية و التي تعنبر أعم من لانكماير وفرندلخ على السطح الغير متجانس ومعادلته الخطية

$\ln Q_{e}=\ln q_{\max }-\beta \varepsilon^{2}$

$\varepsilon=\mathrm{RT} \ln \left(1+\frac{1}{\mathrm{C}_{\mathrm{e}}}\right)$

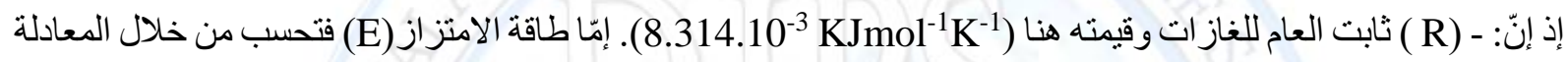

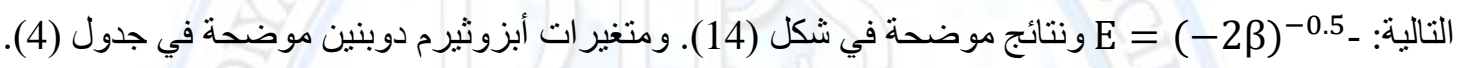

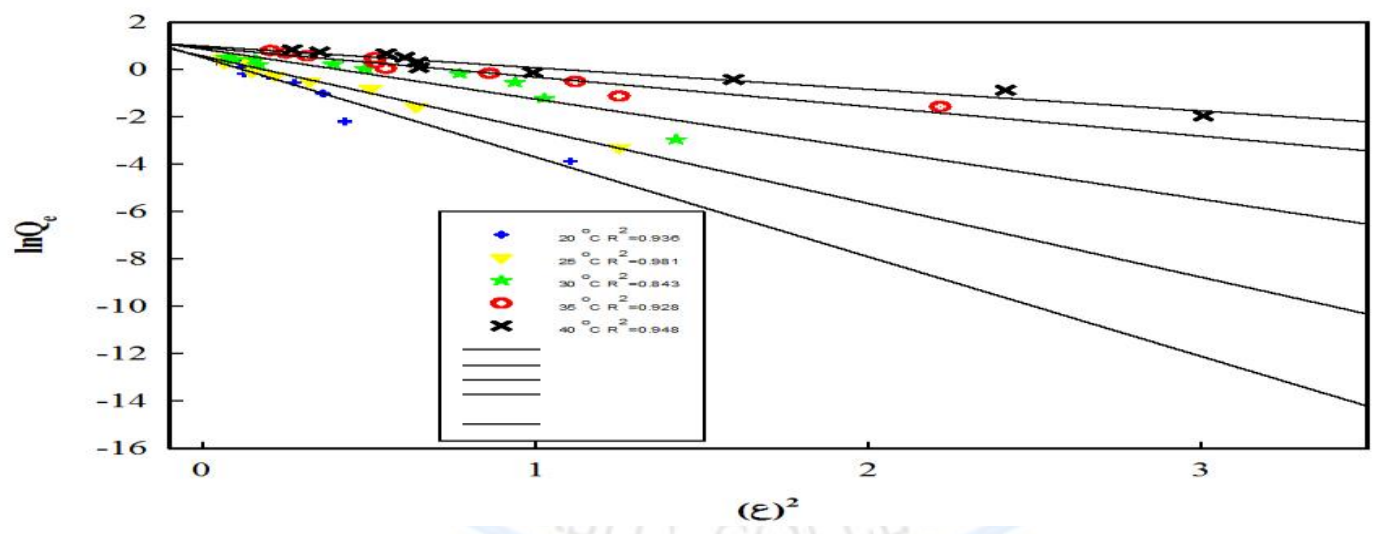

شكل (14) أيزوثيرم دوبنين لصبغة الأيوسين على سطح قثور الحنطة.

إنّ معادلة الطاقة تعطينا تصور عن ميكانيكية الامتزاز، إذ إنّ E<8KJ/mol يدل على ان القوى الفيزيائبة هي المؤثرة على الامتزاز وان E>16 يدل على انتشار الجزيئات و عندما تكون E بين (16-8) يدل على ان الامثزاز يوجه بو اسطة التبادل الايوني الكيميائي، ونتائج الطاقة المدرجة في جدول (4) تتر اوح بين (23.570-10.897) أي إنّ الامتزاز كيميائي. كذللك نجد أنّ الطاقة تزداد مع زيادة درجة الحرارة هذه يتلائم مع قيم الدوال الثرموديناميكية التي تثير إلى أنّ قيمة التغير في

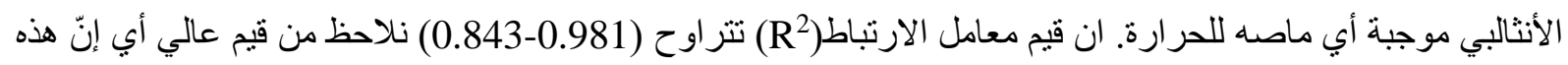
المعادلة تلائم امتز از صبغة الأيوسين على السطح قشور الحنطة، كذلك نجد ان قيمة السعة القصوى للامنزاز ( 


\section{DIVALA JOURNAL FOR PURE SCIENCES}

دراسة امتزاز صبغة الأيوسين على سطح قثشور الحنطة

عبد الرحمن خضير عبد الحسين الطائي مروة إسماعيل مبارك

عامر فاضل داود

مع زيادة درجة الحرارة وهذه يتفق مع كمية المادة الممتزة التي تزداد مع زيادة درجة الحرارة وتتراوح قيمها من

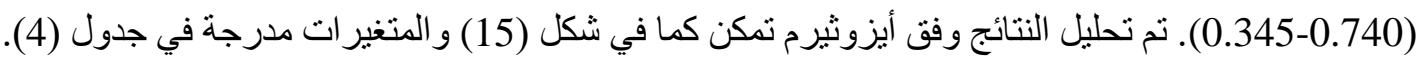
و المعادلة الخطية هي: $Q_{e}=B \ln K_{T}+B \ln C_{e}$

من خلال قيم معامل الارتباط التي تتراوح بين (0.941-0.971) أنّها تلائم امتزاز صبغة الأيوسين على السطح قثنور الحنطة ان أكثر معادلة تلائم امتزاز صبغة الأيوسين على السطح قثور الحنطة هي أيزوثيرم دوبنبن وذلك من خلال قيم معامل الارتباط العالية لها.

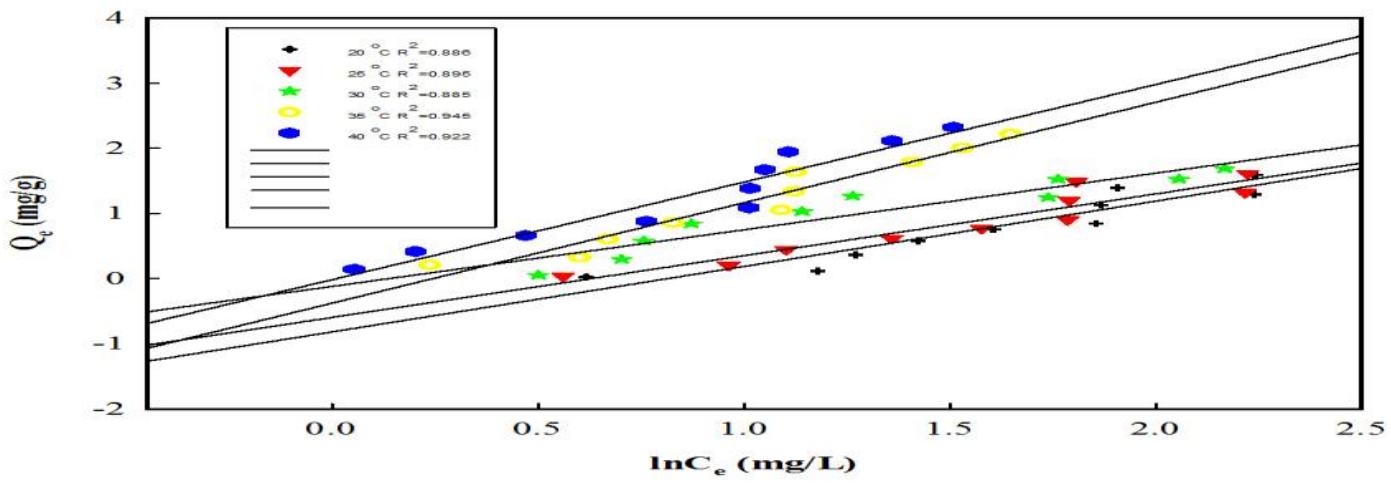

شكل(15) أيزوثيرم تمكن لصبغة الأيوسين على سطح قثنور الحنطة.

جدول (4) متغيرات أيزوثيرم فرندلخ ودوبنين وتمكن لصبغة الأيوسين على سطح قشور الحنطة.

\begin{tabular}{|c|c|c|c|c|c|c|c|c|c|c|}
\hline \multicolumn{4}{|c|}{ فرندلخ } & \multicolumn{4}{|c|}{ دوبنين } & \multicolumn{3}{|c|}{ تمكن } \\
\hline $\mathrm{T}^{\circ} \mathrm{C}$ & $K_{F}$ & $\mathrm{n}$ & $\mathrm{R}^{2}$ & $\boldsymbol{\beta}$ & $\mathbf{q}_{\max }$ & $\mathbf{E}$ & $\overline{\mathbf{R}^{2}}$ & $K_{T}$ & B & $\mathbf{R}^{2}$ \\
\hline 20 & 0.0086 & 0.399 & 0.872 & -0.00421 & 1.662 & 10.897 & 0.936 & 0.442 & 1.004 & 0.941 \\
\hline 25 & 0.029 & 0.506 & 0.847 & -0.00311 & 1.768 & 12.669 & 0.981 & 0.532 & 0.948 & 0.946 \\
\hline 30 & 0.121 & 0.718 & 0.777 & $0.002114-$ & 2.373 & 15.412 & 0.843 & 0.870 & 0.869 & 0.941 \\
\hline 35 & 0.163 & 0.580 & 0.921 & -0.001247 & 2.532 & 20.412 & 0.928 & 0.782 & 1.542 & 0.971 \\
\hline 40 & 0.222 & 0.576 & 0.903 & -0.000913 & 2.694 & 23.570 & 0.948 & 0.988 & 1.498 & 0.960 \\
\hline
\end{tabular}




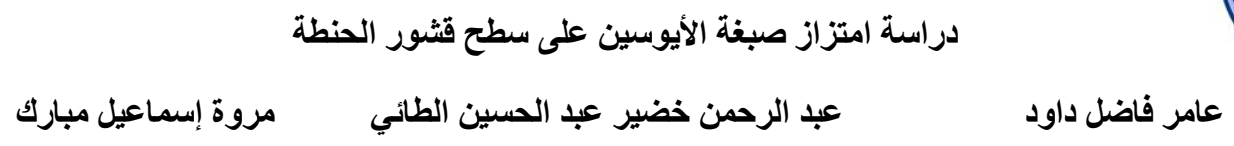

\section{المصادر}

1. Nassar, N.N., Marei, N.N., Vitale, G. and Arar, L.A. (2015), "Adsorptive removal of dyes from synthetic and real textile wastewater using magnetic iron oxide nanoparticles: Thermodynamic and mechanistic insights". Canadian Journal of Chemical Engineering, 93 (11), pp: 1965-1974.

2. Tadesse, B., Teju, E. and Megersa, N. (2015), "The Teff straw: a novel low-cost adsorbent for quantitative removal of $\mathrm{Cr}$ (VI) from contaminated aqueous samples". Desalination and Water Treatment, 56(11),pp: 2925-2935.

3. Wang, Y., Tang, X.W. and Wang, H.Y. (2015), "Characteristics and mechanisms of Ni (II) removal from aqueous solution by Chinese loess". Journal of Central South University, 22 (11), pp: 4184-4192.

4. Memon, F.N. and Memon, S. (2015), "Sorption and Desorption of Basic Dyes from Industrial Wastewater Using Calix[4]arene Based Impregnated Material". Separation Science and Technology, 50 (8), pp: 1135-1146.

5. Foroughi-Dahr, M., Abolghasemi, H., Esmaili, M., Shojamoradi, A. and Fatoorehchi, H. (2015), "Adsorption Characteristics of Congo Red from Aqueous Solution onto Tea Waste". Chemical Engineering Communications, 202 (2), pp: 181-193.

6. Ahmed, M.J. and Theydan, S.K. (2015), "Adsorptive removal of p-nitrophenol on microporous activated carbon by $\mathrm{FeCl} 3$ activation: equilibrium and kinetics studies". Desalination and Water Treatment, 55 (2), pp: 522-531.

7. Ahmadi, M.A. and Shadizadeh, S.R. (2015),"Experimental investigation of a natural surfactant adsorption on shale-sandstone reservoir rocks: Static and dynamic conditions". Fuel, 159, pp: 15-26.

8. Randhawa, N.S., Dwivedi, D., Prajapati, S. and Jana, R.K. (2015), "Application of manganese nodules leaching residue for adsorption of nickel (II) ions from aqueous solution". International Journal of Environmental Science and Technology, 12 (3), pp: 857864.

9. Cao, W., Dang, Z., Yuan, B.L., Shen, C.H., Kan, J. and Xue, X.L. (2014), "Sorption kinetics of sulphate ions on quaternary ammonium-modified rice straw". Journal of Industrial and Engineering Chemistry, 20 (4), pp: 2603-2609. 


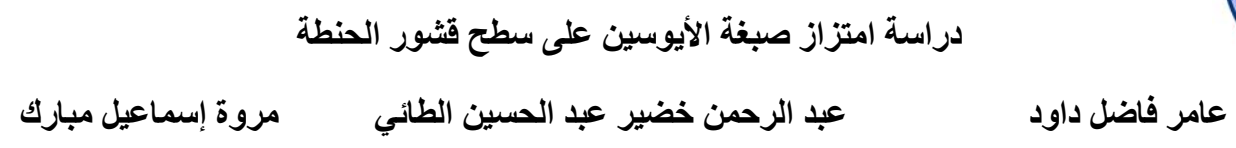

10. Smaranda, C. 1, Gavrilescu, M .1 and Bulgariu, D. 2, (2010), "Studies on Sorption of Congo Red from Aqueous Solution onto Soil ". Al. I .Cuza, University of Iaşi Romania.

11. Chowdhury S., Mishra R., Saha P., Kushwaha P.,(2011), " Adsorption thermodynamics, kinetics and isosteric heat of adsorption of malachite green onto chemically modified rice husk". Desalination, 265(1), pp: 159-168.

12. Douven, S., Paez, C.A. and Gommes, C.J. (2015), "The range of validity of sorption kinetic models". Journal of Colloid and Interface Science, 448, pp: 437-450.

13. Mondal, P. and George, S. (2015)," Removal of Fluoride from Drinking Water Using Novel Adsorbent Magnesia-Hydroxyapatite". Water Air and Soil Pollution, 226, p: 8. 